\title{
5 \\ Supporting the Scholarship of Teaching and Learning at Liberal Arts Colleges
}

\author{
Dolores Peters, David Schodt, Mary Walczak \\ St. Olaf College
}

Although the liberal arts college, with its traditional focus on teaching, may seem like a natural environment for the scholarship of teaching and learning (SoTL), few such institutions participate in national SoTL initiatives. Our associates' experience since 2001 suggests a model for supporting SoTL in teaching-intensive contexts based on faculty ownership, a focus on general education, and some emerging rules of engagement. Because faculty reward systems must validate SoTL if it is to become part of the institutional culture, we also describe one department's efforts to reform its review criteria in order to define scholarly activity broadly.

ince 2000, St. Olaf College has encouraged and supported faculty inter-
Sested in pursuing the scholarship of teaching and learning (SoTL). Approximately 200 colleges and universities have participated in the Carnegie Academy for the Scholarship of Teaching and Learning's (CASTL) Campus Program (2000-2006), which worked with "institutions of all types to cultivate the conditions necessary to support the scholarship of teaching and learning" (The Carnegie Foundation for the Advancement of Teaching, 2006), but St. Olaf is one of only three liberal arts colleges represented among the 96 institutions to have participated in the most recent Campus Program. ${ }^{1}$ We find these statistics somewhat paradoxical given our sense that liberal arts colleges should be fertile ground for SoTL. While we do not pretend to resolve this paradox, we do offer one model for supporting SoTL at liberal arts colleges and at other institutions that share their salient characteristics of relatively small size and a focus on undergraduate education. 
Numbers alone might seem to provide an explanation for the low representation of liberal arts colleges. These institutions comprise a small percentage of the higher education universe, accounting for only $4 \%-5 \%$ of students and a somewhat higher percentage of faculty members. For several reasons, however, we would expect their involvement with SoTL to be greater. Faculty choose liberal arts colleges out of a strong commitment to undergraduate teaching, and smaller classes facilitate the exploration of new approaches to teaching and learning. While most liberal arts colleges have relatively high expectations for traditional scholarship, they typically rank excellence in teaching above research in the reward structure. A recent survey of nearly 500 faculty development leaders showed that $60 \%$ of respondents from liberal arts colleges ranked advancing new initiatives in teaching and learning among their top three goals, compared with $45 \%$ at research institutions (Sorcinelli, Austin, Eddy, \& Beach, 2006). In short, liberal arts colleges appear to be ideal incubators for innovations in teaching and natural candidates for widespread engagement with SoTL.

However, SoTL does not happen automatically, even in contexts where excellent teaching flourishes. As we learned from our experiences at St. Olaf, neither faculty commitment to undergraduate teaching nor a corresponding institutional commitment necessarily translates into SoTL. Most graduate programs do not prepare future faculty for engagement with SoTL, and an institutional commitment to excellence in teaching may not extend beyond the hiring of good faculty who want to teach or an emphasis on teaching in the reward structure.

Nevertheless, supporting SoTL in the liberal arts context makes a great deal of sense, precisely because such institutions, unlike many research universities, do not have to make an argument for the importance of undergraduate teaching. Yet even faculty already heavily invested in teaching and open to new approaches are usually unfamiliar with the vast body of literature that has developed on effective teaching practices. And, despite the supportive environment at liberal arts colleges, the substantial amount of pedagogical innovation that does take place is rarely communicated beyond the individual faculty member's classroom, a result of what Lee Shulman (1993) has identified as pedagogical solitude. SoTL's emphasis on connecting the exploration of one's own teaching problems to an existing body of scholarship on teaching, and on making public the results of these inquiries, addresses both of these problems. For faculty, SoTL can be another way to connect research and teaching; for students, it can provide new opportunities for undergraduate research. Furthermore, the results of this inquiry help make the case for liberal arts colleges to constituencies that may be increasingly skeptical of the value 
of this particular form of higher education. Finally, SoTL offers a way to create a public repository of good practices at the institution and beyond. It can form part of a college's assessment, building from the bottom up on faculty members' genuine interests in teaching well.

Generalizing from the experiences of seven diverse institutions, Cambridge's (2004) recent report on progress in adopting SoTL identifies the following elements as important in fostering this work: involving academic administrators, ensuring a diversity of participants, communicating the results, and working with the reward system. Key to the success of programs designed to support SoTL, however, is the specific way these elements are deployed to match the institutional context in which they function. For example, department chairs may be key academic administrators at some institutions, but not at others where this position may be filled with short-term, rotating appointments. Although having a reward system congruent with SoTL is essential, also significant are whether teaching or research is the highest of the three traditional categories in that system, and in which category SoTL is counted.

A survey of faculty development at a variety of institutions identifies a difference between liberal arts respondents and others that is relevant to the success of programs supporting SoTL. Responses from many liberal arts colleges (and from comprehensive universities) argued for the importance of strong faculty ownership of faculty development. By contrast, at research institutions, the more common perception was that faculty development priorities were set by senior-level administrators (Sorcinelli et al., 2006). Our own experience, while reinforcing the importance of supporting SoTL in ways that are responsive to institutional priorities, also suggests that faculty ownership of these programs cannot be overemphasized. To ensure success in the liberal arts context, programs need to begin by addressing faculty interests, building on local expertise, and creating indigenous models for doing SoTL.

St. Olaf's program for supporting SoTL began with the establishment of our Center for Innovation in the Liberal Arts (CILA). While this learning and teaching center identified SoTL as one of its founding goals, we decided early on to support SoTL as one of many types of activities taking place along a continuum. We wanted to provide direct support for a small number of faculty who would undertake SoTL projects, but we also wanted to encourage larger numbers of faculty who might only be interested in less formal ways of thinking about student learning, such as classroom assessment and "just-intime" teaching.

A cohort of faculty engaged in SoTL is critical to shifting institutional culture from one in which "good teaching" is expected and rewarded to one 
where vibrant conversations about learning are grounded in why and how this learning takes place. This cohort can provide local, credible models for how others might begin to think in new ways about teaching. In economists' language, the spillover effects from even relatively small numbers of faculty engaging in SoTL can be quite large. However, just as it is important to support SoTL, it is equally important to create a "big tent where there is space for small-scale efforts aimed mostly at local improvement as well as more ambitious, sustained, work of a larger scale" (Huber \& Hutchings, 2005, p. 30). Each nourishes the other.

In this chapter, we focus on two aspects of our experience. First is the program of CILA associates. Associates anchor our efforts by creating local models for SoTL inquiry. Each associate receives a one-course released-time award to undertake an SoTL project. Associates also help support CILA's broader activities. As we recount here, their experiences to date have led us to make some important modifications to this program, including the addition of SoTL Learning Communities and the Writing Residency.

Although responsibility for changing the faculty reward system falls outside CILA's administrative mandate, a system that provides appropriate incentives is a vital component of the institutional context that supports SoTL. The second part of this chapter, then, describes our chemistry department's experience revising its standards for tenure and promotion in a way that supports not just excellent teaching, but also a broad definition of scholarship that includes SoTL. St. Olaf's review process is more decentralized than that of some institutions: Statements of Professional Activity developed by individual departments serve as the standard for evaluating faculty work. Nevertheless, as at most liberal arts colleges that rank teaching excellence first among the traditional categories for review, the debate over SoTL at St. Olaf is about whether and how it will be included in scholarship, the second-ranked category for tenure and promotion. Although the process and outcome we describe are specific to our institutional context, we think the work undertaken by the chemistry department illustrates the spillover effect that even a small core of SoTL inquiry can produce and can be a useful model for other departments and colleges.

\section{SoTL and the CILA Associates Program}

Since 2001, five cohorts of CILA associates ( 11 faculty), have undertaken 12 projects that represent the core of SoTL on our campus. Associate professors have provided the highest percentage of participation (7 of 11 associates). Their predominance reflects both campus demographics and national data on 
faculty careers indicating a broadening of professional activities at this rank. A distinctive feature of SoTL on our campus is its engagement of faculty at both extremes of the academic ranks. Full professors' involvement (three associates) is not surprising since senior faculty at liberal arts institutions continue to be fully engaged in teaching. Participation by an instructor in an adjunct position reflects CILA's philosophy of encouraging good teachers at all ranks as well as St. Olaf's policy of considering instructors and adjuncts eligible for many types of faculty development. No assistant professors have yet been associates. Their conspicuous absence probably reflects local and national uncertainty about the status of SoTL in the reward system. For example, at Illinois State University, the lead institution in the CASTL cluster to which St. Olaf belonged, respondents to a survey who were generally favorable toward SoTL were ambivalent about its value and use on campus (McKinney et al., 2003). ${ }^{2}$ Although important initiatives introducing SoTL to junior faculty exist (Reder \& Gallagher, 2007), assistant professors at St. Olaf, as elsewhere, seem more likely to focus on classroom teaching and traditional scholarship than on SoTL.

The humanities, the largest division of the St. Olaf faculty, have provided the largest number of associates (see Table 5.1). Chemistry's prominence among the sciences builds on its long-standing interest in student learning as a legitimate focus of professional activity. Finally, since the environmental studies project in fact focused on visual literacy, there have been two SoTL projects in the fine arts. CASTL has noted fine arts' underrepresentation in So'TL work done in the United States, so our relative overrepresentation of fine arts is atypical.

\section{What Does SoTL at St. Olaf Look Like?}

SoTL inquiry at St. Olaf (see Table 5.2) is similar to the work emerging nationally that Hutchings (2000) has described. Associates are interested in examining what works in the classroom. For example, one studied PowerPoint's effectiveness in introducing visual images into a course. Another wondered which classroom assessments best measure chemistry students' understanding of scientific content and their pre- and post-course attitudes about science. Some studies describe what student learning looks like by observing or articulating constituent components of a classroom experience or technique. An associate examining the effects of EndNote wanted to know how this software for managing bibliographic references encourages students' development as researchers. Still others sought to determine whether the addition of certain desirable components, even if not 
TABLE 5.1

Distribution of SoTL Projects by Area and Department

\begin{tabular}{|ll|}
\hline Area & Total Number of Projects \\
Humanities & 1 \\
English & 1 \\
History & 2 \\
Religion & \\
Social and Applied Sciences & 2 \\
Political science & 1 \\
Psychology & \\
Natural Sciences and Math & 2 \\
Chemistry & 1 \\
Fine Arts & \\
Music & 1 \\
Interdisciplinary and General Studies & 1 \\
Environmental studies & \\
Integrative studies & \\
\hline
\end{tabular}

strictly cognitive, enhances student learning. For example, a notion of the "expertise of discovery" informs the projects of three associates: a historian who wanted students to experience the thrill of constructing meaning out of a mass of primary sources; a political scientist who wanted students to be skillful researchers and to experience the immediacy of researching politics during a presidential primary; a chemist who is passionate about the responsibility of educating informed citizens. "The urgency of training the next generation of scientists," the chemist argued, "occurs in tandem with the need for increasing [scientific and technological literacy] among all citizens. [This urgency] argue[s] for a science-literate population as a means to realizing the life-enhancing potential of science and technology" (CILA Associates, 2005 , report $0405 \mathrm{C}$, p. 1). Finally, as is the case nationally, associates did not focus on explicitly developing new conceptual frameworks that affect teaching practices. 
TABLE 5.2

SoTL Questions Asked by CILA Associates

\begin{tabular}{|c|c|}
\hline $\begin{array}{c}\text { Hutchings's Taxonomy } \\
\text { of SoTL Questions }\end{array}$ & Questions Posed by Associates \\
\hline $\begin{array}{l}\text { What works in the } \\
\text { classroom? }\end{array}$ & $\begin{array}{l}\text { Is PowerPoint an effective pedagogical aid? } \\
\text { What correlations exist between computer-assisted visual presenta- } \\
\text { tions and learning styles? } \\
\text { How can classroom assessment techniques be used to measure } \\
\text { chemistry students' understanding of scientific content and their } \\
\text { pre- and post-course attitudes about science? } \\
\text { How can the web enhance English majors' research skills, especially } \\
\text { in the collaborative process of drafting and revising papers? }\end{array}$ \\
\hline $\begin{array}{l}\text { What does student } \\
\text { learning look like? }\end{array}$ & $\begin{array}{l}\text { What is the effect of bibliographic database management software } \\
\text { (EndNote) on student learning and competence in political science } \\
\text { research? } \\
\text { Can technologically mediated drills in music theory provide greater } \\
\text { interactivity, integration, individualization, and immediate feed- } \\
\text { back for students than existing practices do? } \\
\text { How can the hyperlink capacity of the web foster students' develop- } \\
\text { ment of integrative skills from related fields of study and support the } \\
\text { transferability of knowledge across the boundaries of those fields? } \\
\text { How can image-and-text pedagogy enhance students' capacity to } \\
\text { create sophisticated image-text compositions? } \\
\text { What kind of capstone course best supports seniors with individu- } \\
\text { ally designed majors in their understanding of interdisciplinarity? }\end{array}$ \\
\hline What is possible? & $\begin{array}{l}\text { How can web technology be used in a history survey to enhance } \\
\text { student engagement and provide authentic opportunities for } \\
\text { "doing history"? } \\
\text { How can technology enable students to do political science research } \\
\text { in a more immediate and iterative way, especially in the field? } \\
\text { Can technologically mediated assignments based on mainstream } \\
\text { news articles enhance the scientific and technological literacy of } \\
\text { chemistry students? } \\
\text { How can one develop a model of skill-based virtue ethics in com- } \\
\text { puter science to support students' capacity to integrate ethical con- } \\
\text { cerns with their design of technology? }\end{array}$ \\
\hline
\end{tabular}

Note. Adapted from Hutchings (2000, pp. 4-5). 
SoTL on our campus is overwhelmingly course based and situated in the classroom experiences of individual instructors rather than addressed to the entire curriculum or an academic discipline. Eight projects originated in individual courses where a question or problem had been identified. Even the three projects involving multiple course clusters were based on faculty members' close knowledge of students' patterns of movement through the curriculum, whether across a four-course sequence for music theory majors or three levels of political science coursework.

The majority of our SoTL projects focus on general education (GE) courses. At this point in our SoTL experience, it is unclear whether this characteristic is a differentiating one. In her 2005 keynote address at the first national conference on "Innovations in the Scholarship of Teaching and Learning in Liberal Arts Colleges," Hutchings suggested the tantalizing possibility that SoTL at liberal arts institutions may be particularly well suited to "making connections." In our case, three projects emphasize development of literacies (specifically, visual, scientific, and technological) that transcend particular courses; similarly, one project focuses explicitly on developing ethical thinking. Five focus on research competencies (e.g., gathering and evaluating data, recursive thinking in developing a topic) that students can generalize to a variety of classes. Associates have designed SoTL projects that help students make connections within/across course(s) by integrating old and new knowledge. And the political science project on political analysis during a presidential primary-set in part in New Hampshire-helped students connect experiences inside and outside the classroom by demonstrating that disciplinary research can be experiential learning and even service-learning.

The leitmotiv of GE in associates' work also reveals commonalities with SoTL inquiry nationally. First, since our GE courses are discipline based, the projects reinforce the differentiation of SoTL from traditional educational research. Second, targeting GE courses in research on student learning reflects an emerging consensus that the teaching and learning of critical thinking is grounded in making disciplinary methodology explicit for students and providing them with authentic opportunities to practice it (Wineburg, 2003). Emphasis on teaching critical thinking is shared by faculty across categories of institutional classification: In the Higher Education Research Institute's (HERI) 2004-2005 faculty survey, 99\% of respondents considered development of students' ability to think critically to be "very important" or "essential"; helping students master knowledge in a discipline garnered the second highest endorsement (94\%) as an appropriate goal for undergraduate education (Lindholm, Szelény, Hurtado, \& Korn, 2005). ${ }^{3}$ 
This profile of associates' work highlights faculty ownership of SoTL at St. Olaf, where projects grow out of classroom experience rather than departmental or administrative directives. At the same time, SoTL is not detached from our institutional priorities. All applications for associate positions require a sign-off from the relevant department chair to ensure that discussion has occurred regarding the assignment of faculty time and energy. Moreover, senior faculty's participation means that those conducting SoTL studies may already have been chairs or are chairs during their project year. Nevertheless, our experience clearly suggests a bottom-up rather than top-down pattern of SoTL adoption.

\section{How Does St. Olaf Do SoTL?}

Four informal rules of engagement are emerging as SoTL has developed on campus. First, like many SoTL practitioners, associates have employed a range of methodologies (see Table 5.3) to gather and analyze data and frequently combined methodologies. Similarly, some discovered the need to develop new methodological expertise beyond their own discipline's practices. While this experience is common for faculty new to SoTL, it also has implications for dissemination of SoTL, as we will discuss. The associates' methodological preferences also reveal traces of a particular institutional context. On a campus where faculty frequently solicit student feedback on teaching, student self-reporting is a favorite source of both quantitative and qualitative data. Campus conversations about the pedagogical potential of hyperlink technology echo in the three projects that used electronic portfolios to target cognitive processes or to assess learning outcomes.

A second rule of engagement is the tendency not to use control groups in project design and assessment. A pragmatic explanation for this practice, directly related to institutional context, arises from our low number of multiplesection courses and the fact that even when they exist, responsibility for them is distributed among several faculty. Yet the ethics of SoTL inquiry provide a more complex context for understanding the absence of control groups. Early on, The Carnegie Foundation raised the problematic issue of ethics in a field that straddles traditional research with human subjects, typically requiring review by an institutional review board (IRB), and the collection of classroom data in the aggregate, which has not typically required such review (Hutchings, 2002). In addition, many campuses have recently reconsidered their guidelines for research with human subjects or, in some cases, established IRBs for the first time. St. Olaf is an example of the former; reconsideration of our IRB's organization and procedures occurred just as the first associates 
TABLE 5.3

Methodologies Used in CILA Associates' SoTL Projects

\begin{tabular}{|lc|}
\hline Methodology & Number of Projects \\
Student surveys & 7 \\
Electronic portfolios & 4 \\
Student questionnaires & 3 \\
Student journals and logs & 2 \\
Researcher journal and logs & 2 \\
Content analysis of student assignments & 2 \\
Measurement of student achievement & 2 \\
Classroom assessment techniques & 1 \\
Focus groups & 1 \\
Longitudinal tracking of changed practices & 1 \\
\hline
\end{tabular}

launched their projects. Like all IRBs, ours strives both to protect the rights of human participants and to facilitate research. Like many, ours currently permits expedited review of research involving the collection of anonymous, aggregate classroom data.

We might consider whether an ethos distinctive to teaching-intensive institutions exists in SoTL inquiry. For example, two associates, in disciplines familiar with IRB review, intentionally rejected the use of control groups. One, a political scientist, rejected the practice in part precisely because of ethics: "Despite the explanatory advantages offered by experiments with randomly selected or self-selected test and control groups, I conclude that these experimental research designs suffer from logistical, ethical and/or accuracy problems that outweigh their possible methodological benefits" (CILA Associates, 2003, proposal 0304A, pp. 2-3). Interestingly, this statement reflects faculty opinion frequently expressed in CILA conversations: Using control groups is equivalent to withholding good teaching from students and so is unethical.

A third feature of SoTL engagement involves assessment. SoTL is emerging as a powerful factor in helping to establish a culture of assessment at St. Olaf because it highlights efficacy rather than accountability. At the same time, the range of expertise in assessment is wide, even among advocates of an evidentiary culture. Associates' initial expertise ranged from complete bafflement to the development of a portable set of classroom assessment techniques, to an 
attempt to study changes in student practices across the arc of their undergraduate careers. This range is similar to that among St. Olaf faculty in general. Almost half of those responding to a survey on faculty development in spring 2005 were uncertain how to measure the impact on their students of their participation in CILA conversations about teaching. On the other hand, 31 of the 45 faculty indicating that adoption of new teaching practices had a positive impact on student learning could provide a variety of evidence for this impact (St. Olaf College, 2005).

A final rule of engagement emerged on our campus: SoTL will thrive only if it exists as part of a range of systematic inquiry about teaching and learning. A majority of respondents to the survey reported that they had introduced new teaching practices or changed existing ones as a result of participating in CILA opportunities. Such openness, however, seems unlikely to translate into mass participation in SoTL, at St. Olaf or elsewhere. (At Illinois State, for example, where survey data reveal a generally positive attitude toward SoTL and a significantly higher level of participation in SoTL than on our campus, a statement that all faculty should do SoTL research elicited a neutral response rather than agreement [McKinney et al., 2003].) Perhaps the point is not that even at institutions with a tradition of excellence and innovation in teaching, but rather especially at such institutions, faculty are committed to sustaining choice in the level and nature of their involvement in teaching-related conversations and activities enhancing teaching and learning. Faculty commitment to a range of options echoes even in the plaintive statement of this associate: "During my year as a CILA associate, I have often felt that I am being asked to make a conversion, a full confession of faith in SoTL, when in fact, I have primarily been interested in thinking intentionally about teaching and learning" (CILA Associates, 2005, report $0405 \mathrm{~B}, \mathrm{p}$. 3). The desire to sustain an environment rich in opportunities to address issues in teaching and learning is the obverse of faculty ownership of SoTL and corresponds to Huber and Hutchings's (2005) notion of a "teaching commons" as a broad context supported, but not monopolized, by SoTL.

The SoTL imperative to "go public" with one's findings has not been lost on the associates, who have presented their work in regional, national, and international venues (see Table 5.4). To date, however, little of this work has been published.

\section{Future Challenges and Opportunities}

As we look to the future of So'TL at St. Olaf, we recognize both challenges and opportunities. Some challenges arise from the needs of faculty engaged in SoTL; others relate to institutional culture. 
TABLE 5.4

Dissemination of CILA Associates' SoTL Work

\begin{tabular}{|c|c|}
\hline Type of Dissemination & Number of Presentations/Publications \\
\hline \multicolumn{2}{|l|}{ On-Campus Presentation } \\
\hline CILA brown-bag conversation & 14 \\
\hline Departmental & 2 \\
\hline \multicolumn{2}{|l|}{ Workshop or Symposium } \\
\hline Regional & 2 \\
\hline National & 1 \\
\hline \multicolumn{2}{|l|}{ Conference Paper } \\
\hline Regional & 2 \\
\hline National & 5 \\
\hline International & 2 \\
\hline \multicolumn{2}{|l|}{ Conference Poster } \\
\hline Regional & 2 \\
\hline National & 2 \\
\hline International & 0 \\
\hline \multicolumn{2}{|l|}{ Publication } \\
\hline Regional article & 0 \\
\hline National article & 2 \\
\hline Article in preparation & 6 \\
\hline
\end{tabular}

One challenge for faculty engaged in SoTL is the unexpectedly long time from project inception to publication, as associates' experience suggests. To address this issue, we have established biennial Writing Residencies. Each residency involves three or four faculty in a three-day, off-campus workshop facilitated by an individual experienced in working with faculty on SoTL projects. Participants arrive at the residency with their research completed and five pages (minimum) of a proposed article drafted. During the residency, participants share work, receive constructive feedback, and write intensively. Each participant's goal is to leave with 15 pages written and a clear plan for completing the article. Our writing residency is modeled after the successful Visible Knowledge Project (VKP) centered at Georgetown University (http://cross roads.georgetown.edu/vkp/index.htm). Although the VKP involves faculty 
from multiple and diverse institutions, its main features are translatable to the individual liberal arts college. And, in the interests of sustainability, associates are trained to become in-house facilitators.

Conversations with past associates helped us understand that the primary obstacle to moving SoTL projects to the publication stage is not time but unfamiliarity with how to write in a new scholarly area. Faculty engaged in SoTL projects often need to stretch beyond their disciplinary training. The skills needed to conduct SoTL research overlap only partially with prior training and experience. A quantitative scientist probably lacks training in the kind of qualitative research frequently conducted in the social sciences.

We also learned that interaction with interested colleagues is critical for gaining expertise as faculty undertake SoTL projects. CILA associates have reported feeling isolated at times as they pursue their projects without formal opportunities to engage in sustained conversation with others interested in teaching and learning. For other faculty, lack of experience with SoTL has prevented them from realizing that their work was sufficiently mature to be shared with a wider audience. To support collegiality, we established SoTL Learning Communities, groups of five faculty led by a CILA associate, who spend a year together exploring a teaching and learning topic of common interest. This model of faculty collaboration has been successful on our campus for exploring "just-in-time" teaching and Bransford, Brown, and Cocking's How People Learn (2000).

\section{The Faculty Reward System}

St. Olaf faculty are evaluated in three traditional areas: teaching, scholarship (research), and service. Teaching is the primary consideration in faculty evaluation, as expected at a liberal arts institution. Because scholarship differs across fields, each department has created a Statement of Professional Activity defining scholarly work in its field. After they are approved by a college committee and the dean, these statements are used in the faculty review process. When a candidate is considered for tenure and/or promotion, a copy of the appropriate statement is included in the dossier and sent to the external reviewers of the candidate's scholarship.

St. Olaf's chemistry department has successfully adapted its statement to define scholarship broadly, including SoTL. It has 11 faculty members distributed across all ranks. Historically, its faculty have engaged in traditional laboratory-based scholarly work in the early years of their careers and have branched out into different areas, including SoTL, at some point following tenure. This pattern is consistent with the institutional data presented earlier 
indicating that associate professors are more likely than those at other ranks to engage in SoTL at St. Olaf.

Developed without the involvement of most of the current faculty, the original statement (1986) defined professional activity as "creative and scholarly work in laboratory research, development of new laboratory experiments, and curriculum innovation." This definition explicitly included teaching-related work, as one would expect at a liberal arts institution. It recognized refereed publications as the typical outcome of scholarly work and listed specific works and activities considered scholarship (see Table 5.5).

\section{TABLE 5.5}

\section{Evolution of the Chemistry Department's Standards} for Professional Activity, 1986-2004

\begin{tabular}{|c|c|c|}
\hline \multicolumn{3}{|c|}{ Examples of Acceptable Professional Activity } \\
\hline 1986 & 2001 & 2004 \\
\hline Book & $\begin{array}{l}\text { Laboratory/theoretical investi- } \\
\text { gation of scientific phenomena }\end{array}$ & $\begin{array}{l}\text { Applying/securing resources for in- } \\
\text { dividual growth or maintenance of } \\
\text { department's professional status }\end{array}$ \\
\hline $\begin{array}{l}\text { Refereed articles } \\
\text { (published/accepted) }\end{array}$ & $\begin{array}{l}\text { Innovative development/ } \\
\text { adaptation/implementation } \\
\text { of pedagogy/course content } \\
\text { materials }\end{array}$ & $\begin{array}{l}\text { Classroom/laboratory/theoretical } \\
\text { investigation }\end{array}$ \\
\hline Grant, award & $\begin{array}{l}\text { Scientific writing/presentation } \\
\text { for various audiences, using } \\
\text { library/other forms of investi- } \\
\text { gation }\end{array}$ & Consulting, patent \\
\hline $\begin{array}{l}\text { Review of current } \\
\text { research }\end{array}$ & $\begin{array}{l}\text { Participation/leadership in } \\
\text { professional organization }\end{array}$ & $\begin{array}{l}\text { Participation/leadership in faculty } \\
\text { development workshop }\end{array}$ \\
\hline $\begin{array}{l}\text { Invited presentation } \\
\text { at national meeting }\end{array}$ & Consulting, patent & $\begin{array}{l}\text { Innovative development/ } \\
\text { adaptation/implementation of } \\
\text { pedagogy/course content materials }\end{array}$ \\
\hline $\begin{array}{l}\text { Refereed } \\
\text { presentation at a } \\
\text { national meeting }\end{array}$ & $\begin{array}{l}\text { Securing resources for individ- } \\
\text { ual professional growth or } \\
\text { maintenance of department's } \\
\text { professional status }\end{array}$ & $\begin{array}{l}\text { Involvement in professional organ- } \\
\text { ization from attending meeting to } \\
\text { holding leadership position }\end{array}$ \\
\hline $\begin{array}{l}\text { Activity in national } \\
\text { professional } \\
\text { organization }\end{array}$ & $\begin{array}{l}\text { Peer reviewing grant } \\
\text { proposal/publication }\end{array}$ & $\begin{array}{l}\text { Peer reviewing grant } \\
\text { proposal/publication }\end{array}$ \\
\hline Patent & $\begin{array}{l}\text { Scientific writing/presentation } \\
\text { for various audiences }\end{array}$ & Consulting \\
\hline
\end{tabular}


Departmental review of the statement in 2001 , in preparation for launching a tenure-track search, resulted in a revised document that reflected its members' professional diversity and significantly expanded the definition of scholarship. Two full professors led the revision, which was based on Ernest Boyer's Scholarship Reconsidered (1990). The revised statement endorsed "all professional activity that promotes faculty and student development" and noted the special value of activities involving student collaborators. A broader list of examples of such activities, not intended to be restrictive, emerged (see Table 5.5). For instance, writing and presentations were no longer significant only if peer reviewed or presented at a national meeting. In addition, successful grant writing on behalf of the department was recognized along with grants for individual work.

At the conclusion of its discussions in 2001, the department agreed to review the statement biannually. This review has become a valuable exercise that reminds both current and new faculty members of the range of professional activity in chemistry at St. Olaf.

In 2004 two tenure-track assistant professors and an associate professor proposed broadening the statement further. The revision states that the chemistry faculty "have a diverse set of gifts and talents and we expect members to participate in commensurate professional activities." In addition to activities that promote faculty and student development, the department endorses those that promote programmatic or institutional development. It also reiterates its commitment to faculty-undergraduate collaborations.

An introductory statement delineates what professional activity involves: "Professional activity requires expertise; is conducted cognizant of goals, with the proper preparation and using appropriate methodologies; is recorded and disseminated; is significant to others; and is predominantly assessed by peer review." This revised statement even explicitly names the four areas of scholarship promoted by Boyer and The Carnegie Foundation: those of discovery, application, engagement, and teaching and learning, with brief appended descriptions.

Consistent with its experience and its promotion of professional diversity, the chemistry department states that faculty may choose to conduct different kinds of scholarship at different stages of their careers and need not engage in all kinds. The alphabetically arranged list of examples of scholarly activities discourages ranking one type of activity above another. It recognizes grant proposal preparation (with or without an award), classroom investigations (SoTL), participation in or leadership of faculty development workshops, and diverse forms of involvement in professional organizations (see Table 5.5). 
The department recognizes that diverse forms of professional activity require diverse forms of assessment. While traditional forms of peer review are effective for some products of scholarship, other activities require alternative forms of assessment. The department chair will work with a candidate for tenure and/or promotion who presents such professional activity to determine an appropriate way to assess it. For example, if a faculty member attended a series of faculty development workshops in an effort to improve his or her teaching, evidence of the impact of those efforts could be assessed by examining how the workshop ideas were incorporated into the faculty member's courses.

An important goal of advancing SoTL is its incorporation into faculty evaluation systems. Other departments and institutions will follow different paths to include SoTL in theirs. As an institutional member of the CASTL cluster centered on "Organizing to Foster the Scholarship of Teaching and Learning," St. Olaf helped develop language that can be adapted for use on other campuses to incorporate SoTL into the faculty review process. The cluster's model document focuses on SoTL as work that exhibits methodological rigor, has evident and substantive implications/outcomes, is peer reviewed, and is made public (American Association for Higher Education \& Carnegie Campus Cluster, 2004).

\section{Conclusion}

Engagement with SoTL is consistent with the mission of most liberal arts colleges. It has clear benefits for the institution, and the innovations in teaching and learning that are cultivated in this rich environment can be valuable to faculty in many other institutional settings. Yet as our experience illustrates, engagement with SoTL does not happen even in liberal arts contexts without effective support. To be effective, support for SoTL must be tailored to the particular institutional environment. In the case of the liberal arts colleges and, we suspect, other teaching-centered institutions, the development of credible, local models is critical to success.

\section{Author Note}

We would like to thank the Bush Foundation of St. Paul, Minnesota, for its support of the Center for Innovation in the Liberal Arts at St. Olaf College. We also want to thank Assistant Provost Arnie Ostebee for his unflagging support for faculty development in general and for the scholarship of teaching and learning in particular. 


\section{Endnotes}

1. Liberal arts colleges were identified using the U.S. News \& World Report classification. The Campus Program involves significant institutional commitment, unlike the Carnegie Scholars Program, which is more individual. Seven out of 162 scholars were from liberal arts colleges.

2. In addition, $94 \%$ "indicated that the impact of doing SoTL on their career would be neutral (48\%) or negative (46\%)" (McKinney et al., 2003, p. 5).

3. According to the institutional profile provided by HERI, the numbers for St. Olaf on these two items are $99.1 \%$ and $92 \%$, respectively.

\section{References}

American Association for Higher Education \& Carnegie Campus Cluster. (2004). $T$ and P SoTL language. Retrieved May 15, 2007, from www.cfkeep.org/html/ snapshot.php?id=9244212

Boyer, E. L. (1990). Scholarship reconsidered: Priorities of the professoriate. Princeton, N]: The Carnegie Foundation for the Advancement of Teaching.

Bransford, J. D., Brown, A. L., \& Cocking, R. R. (Eds.). (2000). How people learn: Brain, mind, experience, and school (Expanded ed.). Washington, DC: National Academy Press.

Cambridge, B. L. (Ed.). (2004). Campus progress: Supporting the scholarship of teaching and learning. Sterling, VA: Stylus.

The Carnegie Foundation for the Advancement of Teaching. (2006). CASTL campus program. Retrieved May 15, 2007, from www.carnegiefoundation.org/programs/ sub.asp?key $=21$ \&subkey $=68 \&$ topkey $=21$

Center for Innovation in the Liberal Arts Associates. (2001-2006). Proposals and final reports (0102A-0506B). Northfield, MN: St. Olaf College.

Huber, M. T., \& Hutchings, P. (2005). The advancement of learning: Building the teaching commons. San Francisco, CA: Jossey-Bass.

Hutchings, P. (Ed.). (2000). Opening lines: Approaches to the scholarship of teaching and learning. Menlo Park, CA: The Carnegie Foundation for the Advancement of Teaching.

Hutchings, P. (Ed.). (2002). Ethics of inquiry: Issues in the scholarship of teaching and learning. Menlo Park, CA: The Carnegie Foundation for the Advancement of Teaching. 
Lindholm, J. A., Szelény, K., Hurtado, S., \& Korn, W. S. (2005). The American college teacher: National norms for the 2004-2005 HERI faculty survey. Los Angeles, CA: University of California-Los Angeles, Higher Education Research Institute.

McKinney, K., Broadbear, J., Gentry, D., Klass, P., Naylor, S., \& Virgil, N. (2003). Summary of on-line questionnaire study on the status of SoTL at Illinois State University. Retrieved May 15, 2007, from the Illinois State University, Scholarship of Teaching and Learning web site: www.sotl.ilstu.edu/downloads/pdf/ sotlonlinequest.pdf

Reder, M., \& Gallagher, E. V. (2007). Transforming a teaching culture through peer mentoring: Connecticut College's Johnson Teaching Seminar for Incoming Faculty. In D. R. Robertson \& L. B. Nilson (Eds.), To improve the academy: Vol. 25. Resources for faculty, instructional, and organizational development (pp. 327-344). Bolton, MA: Anker.

Shulman, L. S. (1993, November/December). Teaching as community property: Putting an end to pedagogical solitude. Change, 25(6), 6-7.

Sorcinelli, M. D., Austin, A. E., Eddy, P. L., \& Beach, A. L. (2006). Creating the future of faculty development: Learning from the past, understanding the present. Bolton, MA: Anker.

St. Olaf College, Office of Academic Research and Planning. (2005). Faculty development survey results: Quantitative and qualitative results. Northfield, $M N$ : Author.

Wineburg, S. (2003, April 11). Teaching the mind good habits. The Chronicle of Higher Education, p. B20. 